\title{
Contrapontos entre o universal e o particular: a narrativa apoética da parte e do todo no contexto da modernidade- mundo
}

\section{Francisco Alves Gomes}

- Universidade Federal de Roraima e Universidade Federal de Pernambuco / Boa Vista, RR, Brasil

vrrancisco.ag@ufrr.br

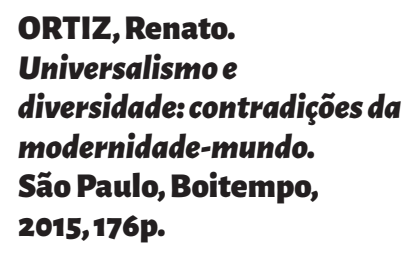
e diversidade: contradições da modernidade-mundo, de autoria de Renato Ortiz, apresenta um debate crítico apoético e incômodo sobre o fenômeno do universalismo moderno, com ênfase na ideologia da diversidade, enquanto símbolo categórico do que o autor prefere chamar de "modernidade-mundo", isto é, a globalização.

Trata-se, na verdade, de um importante trabalho de reconstrução e resgate bibliográfico, teórico e metodológico, de caráter quase artesanal, no qual o autor empenha-se em pontuar os sensos e contrassensos em torno das ideias implícitas e explícitas subjacentes à noção conceitual do "singular" e do "plural", tendo por base as reflexões históricas que embarcam no pensamento grego e desembarcam nas ponderações contextuais contemporâneas, com o fim primeiro, mas não único, de refletir sobre a sensação inaudível de desconforto protagonizado pelo universalismo, enquanto categoria política e filosófica, face ao pluralismo acoplado à ideia de diversidade.

O livro em si é estruturado em cinco capítulos muito bem escritos e dimensionados em forma de ensaios, cujas temáticas distintas interligam-se via litígios acaudilhados sob a mesma designação alegórica, por meio de uma narrativa de linguagem técnica, que conduz o leitor a uma viagem acadêmica com escalas e conexões que problematizam a diversidade, ao mesmo tempo que serve de linha norteadora aos meandros do debate sob a égide da globali- 
zação, tendo-se a acuidade de não se prender ao lugar-comum das discussões enfadonhas e corriqueiras em torno do tema da modernidade-mundo, uma vez que constrói uma leitura própria da temática apresentada.

No primeiro ensaio da obra, objeto de discussão do capítulo 1, Ortiz trata de esclarecer os sentidos originários e circulantes da polissemia das palavras, tendo como escopo, logicamente, os termos "universalismo" e "diversidade". Nesse sentido, para o alcance do alvo pretendido, o autor utiliza-se de subsídios teóricos elementares, sobretudo de pensadores clássicos e contemporâneos das ciências humanas. A partir dessa reflexão teórica, de certo modo incipiente, porém suficiente ao que se propõe, Ortiz chega à conclusão de que determinados conceitos como "humanidade, democracia, cidadania e igualdade tornaram-se valores partilhados e são utilizados para ressignificar as diferenças. A ideia da diversidade como valor universal é um oxímoro" (: 35$)$.

Em outras palavras, a diversidade, então, é compreendida como um oxímoro em razão de ter um formato semântico moldado por uma combinação de palavras de sentidos aparentemente contraditórios, mas que, dentro de um contexto econômico, político, social ou cultural, reforça a expressão e o sentido adotado na narrativa. Assim sendo, "o oxímoro da diversidade é um emblema da contemporaneidade. Cabe ao esforço intelectual desvendar sua expressão e suas ambiguidades" (: 35$)$.

Nessa esteira, observa-se que o proponente dessa ideia lança, em tese, o argumento da crítica compromissada ao fomentar a reflexão ponderada sobre a emergência da diversidade como algoritmo universal, isto é, enquanto valor ecumênico onde jaz o oxímoro. Não obstante, deixa transparecer nas entrelinhas de sua obra que esse "trocadilho semântico" analítico reluz um conflito conveniente, uma vez que qualifica o nicho social que contemplamos na contemporaneidade.

Dentro desta ótica, essa tensão interesseira, ocasionada por tal cenário que cintila nesse novo estágio emblemático da modernidade-mundo, propicia um debate vigoroso no campo das ciências sociais, ponto anteriormente discutido em seu trabalho intitulado A diversidade dos sotaques, publicado em 2008. Essa querela, à luz da história intelectual, vem sendo edificada em diferentes linguagens e sotaques, em vista das transformações e quebras de paradigmas, não apenas nos âmbitos político, econômico e social, mas também no campo intelectual.

Sobre esse assunto, podemos argumentar que em determinado momento histórico vivenciamos a égide dos fundamentos da unidade, a qual denotava homogeneidade. Ao mesmo tempo, em contraposição, vivenciamos o seu inverso, pautado pelos princípios da particularidade, marcando em seu domínio a incumbência do relativismo, em razão da existência da heterogeneidade. Esta análise é muito bem explorada no ensaio atinente ao capítulo 2, momento em que discute-se o papel das ciências sociais frente às transformações de caráter conceitual e de forma, bem como a diversidade das interpretações que, via de 
regra, intensifica o mal-estar do universalismo contemporâneo.

Desse modo, o mal-estar supramencionado surge como resultado do elevado nível de relativismo presente nos estudos e nas ponderações próprias das ciências sociais. Nesse aspecto, destaca-se a forma como Ortiz aborda os diferentes sotaques específicos da área do conhecimento em questão. Ao apropinquar-se da temática, o autor em tela faz uso de um discurso lúcido e realista, utilizando-se de conceitos como imperialismo e alienação cultural para refutar a explicação do mundo a partir da lupa do eurocentrismo.

Entretanto, sem adentrar com entusiasmo e profundidade nos temas, apresenta em linhas gerais os nortes históricos da consolidação das ciências sociais enquanto área do conhecimento científico dotada de um saber autônomo, voltado à compreensão da modernidade-mundo. Nesse contexto, o autor faz uso, principalmente, de dois pensadores clássicos: Émile Durkheim e Max Weber.

As referências a tais autores clássicos justificam-se em razão de serem considerados pela comunidade acadêmica, não sem ressalvas, os principais tradutores (dentre outros) do idioma do raciocínio sociológico no âmbito da leitura do cotidiano. Assim sendo, nas palavras de Ortiz (: 61), "penso ser possível dizer que o idioma das ciências sociais é compartilhado por uma mesma comunidade de falantes, cujos sotaques são, no entanto, distintos".

Em outros termos, o autor quer dizer que as ideias de universalismo e diversidade, por exemplo, são traduzidas de diferentes maneiras no campo das ciências sociais; em virtude disso, afirmamos seu sentido polissêmico, uma vez que a interpretação sociológica e/ou antropológica carrega em seu bojo o carma do relativismo. Ou seja, o significado de universal e de diversidade depende mais ou menos do foco teórico que se adota.

No contexto da globalização, o sentido polissêmico das palavras universal e diversidade demonstra que elas são redesenhadas conforme seus arranjos políticos e sociais, em razão de sua capacidade de movimentação conceitual, mobilística e elástica, bem como da cadeia temporal, representada pela modernidade e pela tradição.

Sobre este tema, Ortiz trata-o em ensaio específico, situado no capítulo 3, devido à importância do assunto e à necessidade de entendimento da influência do ontem e do hoje na formulação das ideias e atitudes locais e globais, à guisa dos constructos teóricos e epistemológicos de Ribeiro e Escobar (2012) sobre a insurgência do "provincianismo metropolitano" e do "cosmopolitanismo provinciano".

Assim sendo, a reflexão em torno da modernidade e da tradição inicia-se via análises etimológicas dos termos, momento em que o estudo preocupa-se em diferenciar conceitos e definições, como antigo/velho e modernidade/antiguidade. Nesse sentido, para o alcance do assunto objetivado, Ortiz faz uso dos estudos de Le Coff $(1984,1990)$ atinentes à temática em questão. Nesses termos, 
o professor da Unicamp adota os mesmos mecanismos utilizados por Le Coff ao recorrer à história semântica das palavras para compreender o dualismo presente nos termos dicotômicos.

Nos ensinamentos de Le Coff (1984), é evidenciado que, no decorrer do período histórico, a sociedade foi capaz de edificar acepções díspares para os termos antigo e moderno, por exemplo. Em outras palavras, com o tempo, esses conceitos tendem a passar por um processo de metamorfose, cuja transformação reflete nada mais, nada menos que os arquétipos ideológicos de cada tempo e espaço e, por vezes, ultrapassa as barreiras da história, sobretudo na história narrativa do Ocidente.

Nas palavras de Ortiz (: 89), "[...] recuperar alguns desses argumentos (não todos) e compreendê-los seria talvez uma maneira de esclarecer questões presentes". Diante disso, o autor faz uso do referido artifício analítico para edificar a arqueologia das ideias, com o olhar esperançoso e utilitarista de que tal constructo teórico seja útil para a releitura dos fenômenos dos tempos atuais. No entanto, cabe destacar que a leitura elaborada pelo autor é retrospectiva e interessada, uma vez que privilegia o aspecto da diferença.

No que se refere a esta vertente centralizada na diferença, torna-se evidente tal perspectiva adotada por Ortiz (2015) no ensaio da quarta parte de sua obra. Assim sendo, no capítulo 40 autor enfatiza a eminência do relativismo cultural no contexto do universal ismo e da diversidade, utilizando-se, como sempre, do instrumento analítico da arqueologia das ideias como ponte de safena para o entendimento dos fenômenos de nosso tempo.

Neste aspecto, é oportuno salientar que o referido ensaio configura-se, talvez, como o mais proeminente de sua obra, em virtude de abarcar em um curto espaço textual uma gama de caracteres e ponderações genuinamente antropológicas, muito bem conectadas, acerca do debate sobre o relativismo cultural, que em sua acepção assenta-se num pressuposto pautado na inteireza absoluta da cultura.

Não se trata tanto de postular seu isolamento, afinal, por mais sólidas que sejam as fronteiras, os grupos sociais interagem entre si. A rigor, a temática do contato é uma dimensão importante dos estudos culturalistas [...]. O problema é a noção de inteireza que permite associar a cultura às metáforas do caráter e da identidade. Nesse sentido, ela seria um Ser que se conjug a no singular. O pluralismo na visão relativista é, na verdade, uma justaposição de singularidades (: 111).

Em outras palavras, o autor tece uma crítica à tendência relativista de concentrar, de modo absoluto, todos os seus esforços na esfera cultural, tomando a cultura como a totalidade da vida social, e não apenas uma de suas dimensões; ou seja, nesse campo, o plural torna-se mais adequado que o singular. No entanto, o debate sobre o relativismo tende a reificar a cultura como uma entidade 
singular repleta de representações simbólicas.

Desse modo, analisando as colocações acima fornecidas, identificamos implicitamente um itinerário intelectual calcado em Bourdieu (2007), principalmente quando Ortiz (2015) refere-se à noção de cultura enquanto representações simbólicas de uma entidade singular. Na concepção bourdieusiana, a noção de cultura é compreendida "[...] como um conjunto comum de esquemas fundamentais previamente assimilados, e a partir dos quais se articula [...] uma infinidade de esquemas particulares diretamente aplicados a situações particulares" (Bourdieu, 2007: 208-209).

Esse arquétipo bourdieusiano de pensar a cultura inculta nas arestas desse debate a necessidade de se rever certas correntes de pensamento enquanto processos epistemológicos de construção e/ou consolidação da ciência, isto é, enquanto forma de evadir-se do mito adâmico, conforme destacado por Ortiz, tal como procedeu Boas (2010), ao concentrar esforços na desvinculação da cultura e da língua em relação à raça, na qual estiliza o modelo de superação das falácias para além do status quo, conforme prognósticos de Kuhn (2000).

A esse respeito, inclusive, encontramos no último ensaio da obra em análise, referente ao capítulo 5, uma tentativa aproximada desse processo de fissura de paradigmas e rupturas epistemológicas no contexto das ciências sociais. Ortiz propõe, mesmo que indiretamente, uma leitura da diversidade conglomerada ao ineditismo quando efetiva sua análise da ressignificação do termo em questão no contexto do discurso empresarial, tendo por princípio basilar as transformações do mundo contemporâneo.

Nesse sentido, a noção de "diversidade" faz-se presente nos itinerários sociais dos "agentes promotores dos arranjos produtivos locais e globais", os quais o autor denomina "homens de empresas". Isto posto, "uma maneira de compreender o sentido do diverso, da diferença, é retomar o debate sobre a globalização que se faz entre os executivos das corporações transnacionais e os homens de marketing nos anos 1980" (: 114).

Em outros termos, o autor defende, neste momento, que a observação conjuntural da globalização, enquanto processo, pode servir como termômetro analítico à medida que demonstra uma não ficção comum entre mercados e procedimentos globais. Todavia, as distinções apresentam-se no campo cultural. É exatamente em razão desse detalhe hermético que o debate acerca da diversidade deve centra-se sobre a esfera cultural. Paralelo a essa discussão, observa-se que, apesar da centralidade analítica adotada por Ortiz em relação à globalização, o presente ensaio não se prolonga nas explicações, muito menos adentra no debate academicista no que pese a modernidade-mundo.

Paralelo a esse ponto, um norte importante que observamos tem a ver com o destaque à noção de espaço, que o autor sublinha como determinante para o 
diagnóstico dos novos tempos. Sendo assim, o olhar macro torna-se necessário, uma vez que favorece uma estratégia de singularização do mundo, momento em que o proponente enaltece a necessidade de se compreender o todo em detrimento das partes.

Nesse contexto, temos duas vertentes: por um lado, os estudos sobre a globalização, que ressaltam o calibre da unicidade do orbe, por outro, a corrente pós-moderna, que aquilata a diferença. Em virtude disso, Ortiz (: 116) destaca a "tensão entre o único e o diverso, o plano e o caleidoscópio das idiossincrasias locais".

Além de destacar a importância da noção de espaço para a compreensão da contemporaneidade, a obra de Ortiz tem por mérito a ilustração da discussão bibliográfica sobre o lugar da diversidade na literatura específica da área de comércio e marketing. É salutar mencionar o cuidado que o autor tem no trato das palavras. Nesta parte do ensaio, Ortiz evita a utilização do termo "diversidade", pois ele explica que essa palavra inexiste na literatura consultada. Por isso, opta por empregar os termos "diverso" e "diferença" em várias passagens do texto.

O quadro discursivo destacado acima reforça as assertivas de Fleury (2000) acerca das experiências das empresas brasileiras no âmbito do gerenciamento da diversidade cultural do país. Nessa esteira, apesar do contexto cultural diversificado em que atuam as empresas nacionais, a temática da diversidade cultural ainda é recente nas agendas de discussões. No entanto, torna-se cada vez mais latente a implementação de estudos que focalizem essa temática, pois, se uma organização detém uma identidade, o mote da diversidade é determinante, conforme entende Ortiz.

Nessa perspectiva, os trabalhos de Taylor Cox $(1991 ; 1994)$ evidenciam muito bem esse novo paradigma de mercado, cujo lema denuncia a seguinte constatação: se não há debate, não tem como haver reflexão crítica efetiva sobre o tema, nem uma arqueologia semântica e etimológica dos termos e seus conectores. De acordo com esse autor, a gestão da diversidade implica, dentre outros, o planejamento e a execução de processos e práticas gerenciais de pessoas, tendo como foco a potencialização da diversidade, evitando-se, assim, seus percalços no seio da empresa e na lógica do mercado (Cox, 1994).

As assertivas de Cox são ilustradas com maestria na obra de Ortiz, que faz uso do pensador contemporâneo para estilizar seu ponto de vista sobre gestão da diversidade no contexto empresarial. Contudo, o autor vai mais além ao tecer críticas aos livros e artigos que "são escritos no imperativo e lembram incessantemente a necessidade de não perder de vista os objetivos práticos dos empreendimentos" (:125).

Sobre este assunto, Alves e Galeão-Silva (2004) apontam que a literatura internacional específica sobre o tema defende que a gestão da diversidade é mais efetiva para o combate das desigualdades sociais por usar variáveis de meritocracia e permitir o alcance das benesses econômicas para os indivíduos 
e as empresas. No entanto, esses mesmos pesquisadores contradizem os argumentos da literatura internacional ao concluir que:

[...] A transposição dessas práticas para o contex to brasileiro, porém, encontra um elemento complicador em sua adoção quando se considera a ideologia da democracia racial brasileira, que mascara o preconceito e entra em tensão com a ideologia da gestão da diversidade (Alves e Galeão-Silva, 2004, p. 1).

Nesta perspectiva, corroborando Alves e Caleão-Silva (2004), Ortiz (: 137) aduz que "os textos de administração de empresa dão-nos algumas vezes a impressão de um prodigioso hibridismo intelectual". Em outros termos, entende-se que, no constructo teórico fundante do ideal empreendedor, o discurso empresarial é convincente, uma vez que nos leva a uma rede de sentidos que ultrapassa a simples barreira do instrumental. Ou seja, conceitos como reconhecimento, pluralismo, respeito e cidadania são provocados verbalmente, na ordem do discurso, enquanto simples enunciação de uma estratégia de marketing no divã da modernidade-mundo.

Portanto, diante do que foi brevemente exposto, cabe destacar que Ortiz apresenta sua visão crítica; porém, adota um exame superficial do que se propõe, desde a análise arqueológica conceitual e semântica dos termos "universalismo" e "diversidade", passando pela crítica à proposta culturalista, até chegar na apresentação de um arcabouço teórico alternativo, que corresponda às transformações conceituais e semânticas do mundo contemporâneo, sem se "deixar levar" pela não menos fácil reverência aos fundadores das discussões atinentes ao tema.

Estudos como este apresentado pelo autor revelam o quanto de novo um pesquisador insistente pode extrair dos temas mais usuais da contemporaneidade, temas estes que pareciam claramente esgotados. Ledo engano. Com exceções de afinação acadêmica e instrução científica, Ortiz compõe uma obra digna de resenha crítica enquanto instrumento clássico do exercício epistemológico praticado por um pensador em intensa harmonia com o seu tempo, com este mundo contemporâneo repleto de transformações e crises típicas da diversidade da modernidade-mundo.

Francisco Alves Gomes é mestre (2013) e doutorando em Antropologia Social pela Universidade Federal de Pernambuco. Atualmente, é Professor Efetivo da Carreira do Magistério de Ensino Básico, Técnico e Tecnológico - EBTT, do Colégio de Aplicação da Universidade Federal de Roraima - UFRR. Foi Professor Efetivo do Instituto Federal de Educação, Ciência e Tecnologia de Roraima - IFRR (2016). 


\section{REFERÊNCIAS BIBLIOCRÁFICAS}

ALVES, Mario Aquino e CALEÃO-SILVA, Luis Cuilherme

2004 "A crítica da gestão da diversidade nas organizações". Rev. adm. empres., São Paulo, v. 44, n. 3: 20-29.

BOAS, Franz

2010 A mente do ser humano primitivo. São Paulo, Editora Vozes.

BOURDIEU, Pierre

2007 A economia das trocas simbólicas. São Paulo, Perspectiva.

COX, Taylor

1991 "The Multicultural Organization". The Executive, v. 5, n. 2.

1994 Cultural Diversity in Organizations: Theory, Research and Practice. São Francisco: Berrett-Koehler Publishers.

FLEURY, Maria Tereza Leme

2000 "Cerenciando a diversidade cultural: experiências de empresas brasileiras". Rev. adm. empres., São Paulo, v. 40, n. 3: 18-25.

KUHN, Thomas

2000 A estrutura das revoluções científicas. São Paulo, Perspectiva.

LE GOFF, Jacques

1984 “Antigo/moderno". In ROMANO, Ruggiero (org.), Enciclopédia Einaudi. Lisboa, Imprensa Nacional - Casa da Moeda.

1990 História e memória. Campinas, SP, Editora da Unicamp.

ORTIZ, Renato

2008 A diversidade dos sotaques: o inglês e as ciências sociais. São Paulo, Brasiliense.

RIBEIRO, Gustavo Lins e ESCOBAR, Artur (orgs.)

2012 Antropologias mundiais: transformações da disciplina em sistemas de poder. Brasília. Editora UnB. 